\title{
Willingness to participate in a lifestyle intervention program of patients with type 2 diabetes mellitus: a conjoint analysis
}

This article was published in the following Dove Press journal:

Patient Preference and Adherence

I November 201।

Number of times this article has been viewed

\author{
Paul F van Gils' \\ Mattijs S Lambooij' \\ Marloes HW Flanderijn' \\ Matthijs van den Berg \\ G Ardine de Wit ${ }^{1,3}$ \\ Albertine J Schuit ${ }^{1,4}$ \\ Jeroen N Struijs' \\ 'Centre for Prevention and Health \\ Services Research, National \\ Institute for Public Health and \\ the Environment, Bilthoven, the \\ Netherlands; ${ }^{2}$ Centre for Public \\ Health Forecasting, National \\ Institute for Public Health and \\ the Environment, Bilthoven, the \\ Netherlands; ${ }^{3}$ Julius Centre for Health \\ Sciences and Primary Care, University \\ Medical Centre Utrecht, Utrecht, the \\ Netherlands; ${ }^{4}$ Department of Health \\ Sciences, EMGO Institute for Health \\ and Care Research, VU University, \\ Amsterdam, the Netherlands
}

Correspondence: Paul F van Gils Centre for Prevention and Health Services Research (pb I0I), National Institute of Public Health and the Environment, PO Box I, 3720 BA Bilthoven, The Netherlands

Tel +3। 30274858 I

Fax +3। 302744407

Email paul.van.gils@rivm.nl
Background: Several studies suggest that lifestyle interventions can be effective for people with, or at risk for, diabetes. The participation in lifestyle interventions is generally low. Financial incentives may encourage participation in lifestyle intervention programs.

Objective: The main aim of this exploratory analysis is to study empirically potential effects of financial incentives on diabetes patients' willingness to participate in lifestyle interventions. One financial incentive is negative ("copayment") and the other incentive is positive ("bonus"). The key part of this research is to contrast both incentives. The second aim is to investigate the factors that influence participation in a lifestyle intervention program.

Methods: Conjoint analysis techniques were used to empirically identify factors that influence willingness to participate in a lifestyle intervention. For this purpose diabetic patients received a questionnaire with descriptions of various forms of hypothetical lifestyle interventions. They were asked if they would be willing to participate in these hypothetical programs.

Results: In total, 174 observations were rated by 46 respondents. Analysis showed that money was an important factor independently associated with respondents' willingness to participate. Receiving a bonus seemed to be associated with a higher willingness to participate, but having to pay was negatively associated with participation in the lifestyle intervention.

Conclusion: Conjoint analysis results suggest that financial considerations may influence willingness to participate in lifestyle intervention programs. Financial disincentives in the form of copayments might discourage participation. Although the positive impact of bonuses is smaller than the negative impact of copayments, bonuses could still be used to encourage willingness to participate.

Keywords: incentives, bonus, copayment, conjoint analysis, willingness to participate

\section{Background}

Lifestyle intervention programs can be defined as a planned and targeted approach to change the behavior of people with the aim of promoting health or preventing disease. Lifestyle intervention programs can have a positive impact on public health, for example, by reducing risk factors for diabetes complications like high blood pressure, high cholesterol level, and high body weight. ${ }^{1-3}$ These interventions could potentially also slow down the increasing prevalence of type 2 diabetes mellitus, ${ }^{4-6}$ expected to be 366 million worldwide by the year 2030 . $^{7}$

A major challenge in lifestyle intervention programs is to increase willingness to join, as participation in such programs is in general relatively low. For instance, a weight-loss program for obese patients in the United States only had a $40 \%$ participation rate, ie, adherence and compliance..$^{89}$ Also, only $15 \%$ of eligible persons participated in a German disease management program. ${ }^{10}$ In the latter study, the main 
reason for participation was that their health insurer offered clients to join.

The lower the participation rate in a lifestyle program, the smaller the public health impact might be. ${ }^{8,11}$ It is therefore important to get a better understanding of peoples' willingness to participate in lifestyle intervention programs. There are different techniques to measure why people participate in interventions. One of them is the conjoint analysis technique. ${ }^{12-15}$ This quantifies the relative importance of characteristics of a lifestyle intervention in program participation decisions. Obviously, this information can also be used to explore why people are not willing to participate in lifestyle intervention programs. Previous conjoint analysis study results suggest that people are willing to pay to participate in lifestyle interventions but they do not seem willing to pay full program costs. ${ }^{16}$ Moreover, individuals with high perceived risks seem willing to pay more compared with individuals with low perceived risks. An alternative technique for conjoint analysis is to use a standard questionnaire and simply ask why people decided to (or not) participate in a lifestyle intervention program. Studies that investigated reasons for not participating using this technique, suggest that affordability is a barrier to participate. ${ }^{17,18}$ For instance, potential participants indicate that they cannot afford to pay the relatively higher prices for better quality food or they cannot afford to pay for use of sport facilities. The conjoint analysis and standard questionnaire findings suggest that money is associated with participation in lifestyle intervention programs. Germany seems the first country to use positive financial incentives (bonuses) to encourage active participation in primary and secondary prevention. ${ }^{19}$

To the best of the authors' knowledge no empirical research has been performed to analyze the effect of various types of financial incentives on participation in lifestyle intervention programs. The main aim of this paper is to explore empirically potential differences of two types of financial incentives on diabetes patients' willingness to participate in lifestyle interventions. One financial incentive is negative ("copayment") and the other is positive ("bonus"). The key part of this research is to contrast both incentives. The secondary aim is to examine which other factors of a lifestyle intervention program are associated with diabetes patients' willingness to participate.

\section{Methods}

\section{Conjoint analysis}

The conjoint analysis technique was used to examine which factors are associated with willingness to participate in a hypothetical lifestyle intervention program. In a conjoint analysis a hypothetical lifestyle intervention program is described in terms of characteristics (attributes). The technique presents hypothetical scenarios (vignettes) to respondents that vary with respect to the levels of the attributes. ${ }^{20}$ Respondents are asked if they would be willing to participate in the hypothetical lifestyle intervention program. Conjoint analysis has an important advantage compared with standard questionnaire research: people are forced to make trade-offs and they cannot indicate that all factors of a lifestyle intervention program are of equal importance.

\section{Literature to determine conjoint scenarios}

A literature search was carried out to determine the vignette attributes. Search terms were: lifestyle program, lifestyle modification, physical activity, exercise, adherence, compliance, and participation. For this search the databases PubMed, Cochrane, PsycINFO, and Picarta were used.

Factors that seem to influence willingness to participate in lifestyle intervention programs include time, costs, counseling, the kind of sports activity in the program, and the composition of the group. ${ }^{17,18,21-24}$ Based on the literature findings six attributes were created. They are presented in Table 1. Next, levels were assigned to the attributes. Majority of the attribute levels were dummies and the money attributes were

Table I Attributes and levels

\begin{tabular}{ll}
\hline Attribute & Levels \\
\hline Time spent on the program & 2.5 hours per week \\
& 4 hours per week \\
Arrangement physical & Individually with men and women \\
activity lessons & With people of the same gender \\
Group activity & Only with people without \\
& diabetes \\
& Only with other diabetes patients \\
Sports activity & Walking/cycling \\
& Fitness (treadmill, rowing \\
Counseling & machine, bicycle) \\
& None \\
Money & Physical therapist/sports teacher \\
& Copayment $=€ 500$ per year \\
& Copayment $=€ 327.50$ per year \\
& Copayment $=€ I 55$ per year \\
Copayment $=€ 0$ per year \\
Bonus $=€ 0$ per year \\
Bonus $=€ I 55$ per year \\
Bonus $=€ 327.5$ per year \\
Bonus $=€ 500$ per year
\end{tabular}

Notes: *Half of the research population received a conjoint questionnaire in which they had to pay for participating in the hypothetical lifestyle intervention. The other half received a questionnaire in which they received money for participation. 
chosen in a range wide enough to likely influence respondents hypothetical choices. Obviously, how much they influence the hypothetical choices is the empirical question trying to be answered.

The main aim of this study was to test for potential differences between a negative (copayment) and a positive (bonus) financial incentive to participate in hypothetical lifestyle intervention programs. Therefore, the research population was randomly divided into two groups. One group received a conjoint questionnaire in which they had to pay a hypothetical copayment to participate in the hypothetical lifestyle intervention and the other group received a conjoint questionnaire in which they received a hypothetical bonus to participate in the hypothetical lifestyle intervention. Please note that all other attributes were exactly similar between both versions of the conjoint questionnaire. Appendix A presents the details of the design of the conjoint experiment that was used in this study.

\section{Study population}

Patient questionnaires were distributed in 2009 among type 2 diabetes patients by two specialized nurses in general practices. None of the diabetes patients had previously participated in a lifestyle intervention program, nor had complications or comorbidities. One nurse distributed 63 questionnaires to patients visiting the clinic and another nurse sent out 192 questionnaires to a random selection of her patients. All respondents were asked to complete the conjoint analysis on a voluntary basis. The study did not require approval of a medical ethics committee as the questionnaire did not include questions which can intervene in the psychological state of the participants.

\section{Statistical analysis}

Respondents' characteristics were analyzed using frequencies. A logistic regression was used to analyze conjoint scenarios as the focus was on the willingness of respondents to participate in the hypothetical lifestyle program: answering categories yes vs no. Results of the linear probability model were also presented for ease of interpretation. The influence of respondents' characteristics on the willingness to participate in a lifestyle intervention program was also analyzed. The statistical program used for the analyses was Stata (v 11; StataCorp LP, College Station, TX).

As the key part of the analysis was to test for potential differences between the hypothetical copayment and bonus, a spline was included in the logistic regression analyses. A spline is a combination of variables in a regression analysis.
It consists of a main effect, a dummy variable indicating a possible bend in the regression slope (the knot), and an interaction variable. The spline enables a test of whether the slope of the copayment differs from the slope of the bonus. ${ }^{25}$ In other words, it was tested if the coefficients of copayment and bonus have the same impact on willingness to participate using an F-test. Moreover, the dummy variable enables a test for whether respondents' values for not receiving a bonus and not having to pay copayment differ between scenarios in which they received a bonus compared with scenarios in which they had to pay a copayment. The main reason for including a spline in the regression models is that people might react differently to a scenario with a negative financial incentive compared with a scenario with a positive financial incentive. Appendix B gives a detailed explanation of the construction of the spline and a detailed explanation of its interpretation.

\section{Results}

\section{Study population}

In total, 174 observations were rated by 46 respondents (18\% of the distributed questionnaires) implying that not all respondents answered four conjoint scenarios.

The majority of respondents were Dutch (97.7\%), and men and women were equally represented (50.0\%). Their mean age was 67.3 years (standard deviation 11.2) and about $25 \%$ was above 75 years of age. Mean body mass index (BMI) was $28.8 \mathrm{~kg} / \mathrm{m}^{2}$ (standard deviation 5.7). Twenty percent of the respondents had a low income and most of them were retired (53.7\%). As the characteristics age, sex, nationality, and BMI of this study population correspond to those characteristics found in a large observational study on diabetic patients in the Netherlands, ${ }^{26,27}$ this sample can be considered representative of the Dutch diabetic population.

\section{Regression analyses}

Table 2 presents the results of the regression models without correction for confounders. The signs of the logistic regression coefficients (B) represent the relations between the attribute levels and respondents' willingness (or not) to participate. The $P$ values are only statistically significant for the attribute "money" $(P=0.01)$ and the interaction "money*receiving" $P=0.050)$. As only these money attributes are statistically significant, it seems that only money influences willingness to participate. The positive sign of the "money" attribute suggests a positive association between money (either a bonus or a decreasing copayment) and willingness to participate. The negative sign of the interaction "receiving*money" indicates 
Table 2 Results of regression models based on the attributes of participation in the hypothetical lifestyle interventions ( $N=46 ; \mathrm{N}$ observations $=174$ )

\begin{tabular}{|c|c|c|c|c|c|c|c|}
\hline \multirow[t]{2}{*}{ Attributes } & \multicolumn{4}{|c|}{ Logistic regression model } & \multicolumn{3}{|c|}{ Linear probability model } \\
\hline & B & Odds ratio & $95 \% \mathrm{Cl}$ & $P$ value & B & $95 \% \mathrm{Cl}$ & $P$ value \\
\hline \multicolumn{8}{|l|}{ Time spent on the program } \\
\hline \multicolumn{8}{|l|}{ (reference category $=2.5$ hours) } \\
\hline 4 hours & -0.067 & 0.935 & 0.448 to 1.953 & 0.863 & -0.018 & -0.162 to 0.126 & 0.803 \\
\hline \multicolumn{8}{|l|}{ Arrangement of physical activity lessons } \\
\hline \multicolumn{8}{|l|}{ (reference category = with men and women) } \\
\hline With people of the same gender & 0.577 & 1.780 & 0.729 to 4.347 & 0.243 & 0.098 & -0.072 to 0.269 & 0.249 \\
\hline Individually & 0.405 & 1.500 & 0.622 to 3.619 & 0.402 & 0.066 & -0.102 to 0.235 & 0.432 \\
\hline \multicolumn{8}{|l|}{ Group activity } \\
\hline \multicolumn{8}{|l|}{ (reference category = only with people without diabetes) } \\
\hline Only with other diabetes patients & 0.490 & 1.633 & 0.786 to 3.392 & 0.168 & 0.088 & -0.041 to 0.218 & 0.176 \\
\hline \multicolumn{8}{|l|}{ Sports activity } \\
\hline \multicolumn{8}{|l|}{ (reference category = walking/cycling) } \\
\hline Fitness (treadmill, rowing machine, bicycle) & 0.467 & 1.595 & 0.771 to 3.296 & 0.206 & 0.076 & -0.058 to 0.209 & 0.258 \\
\hline \multicolumn{8}{|l|}{ Counseling } \\
\hline \multicolumn{8}{|l|}{ (reference category $=$ no counseling) } \\
\hline Counseling from a physical therapist/sports instructor & $0.28 \mathrm{I}$ & 1.325 & 0.631 to 2.783 & 0.513 & 0.046 & -0.110 to 0.203 & $0.55 I$ \\
\hline Money & 0.006 & 1.006 & 1.002 to 1.011 & 0.025 & 0.0008 & 0.000 to $0.00 \mathrm{I}$ & 0.014 \\
\hline \multicolumn{8}{|l|}{ Copayment $=€ 500$ per year } \\
\hline \multicolumn{8}{|l|}{ Copayment $=€ 327.50$ per year } \\
\hline \multicolumn{8}{|l|}{ Copayment $=€ 155$ per year } \\
\hline \multicolumn{8}{|l|}{$€ 0$ per year } \\
\hline \multicolumn{8}{|l|}{ Bonus $=€ । 55$ per year } \\
\hline \multicolumn{8}{|l|}{ Bonus $=€ 327.50$ per year } \\
\hline \multicolumn{8}{|l|}{ Bonus $=€ 500$ per year } \\
\hline Receiving & -0.429 & 0.651 & 0.220 to 1.930 & 0.579 & -0.051 & -0.370 to 0.266 & 0.744 \\
\hline Interaction receiving*money & -0.006 & 0.994 & 0.990 to 0.999 & 0.050 & -0.0006 & -0.002 to 0.000 & 0.126 \\
\hline Intercept & -1.258 & 0.284 & 0.098 to 0.827 & 0.045 & 0.226 & -0.017 to 0.468 & 0.067 \\
\hline
\end{tabular}

Abbreviations: $\mathrm{Cl}$, confidence interval; $€$, euro.

that the effect on participation is smaller in the case where the patient receives a bonus. The negative coefficient of "receiving" reflects the difference of the zero option (the value of 0 of the attribute money) between respondents which had answered conjoint scenarios with only bonuses vs conjoint scenarios containing only copayments.

The corresponding coefficient of the linear probability model suggest that money increases the willingness to participate in a lifestyle intervention program with $0.08 \%$ per euro increase in bonus or decrease in copayment $(\mathrm{B}=0.0008)$. However, the statistically significant interaction variable of the spline $(\mathrm{B}=-0.057 ; P=0.050)$ suggests that the slope for paying money differs from the slope of receiving money. For paying money the slope is positive (main effect of money $\mathrm{B}=0.0008 ; P=0.014)$, but for receiving money the slope flattens out (for receiving money the $\mathrm{B}$ of the interaction variable "money*receiving" is added to the main effect $[0.0008+-0.0006=0.0002])$. The (nontabulated) F-test was significant for both linear and logistic analyses (linear
$\mathrm{F}=4.93, P=0.032$; logistic $\mathrm{F}=4.73, P=0.029)$. Although the coefficients of the slope of receiving seem very small, in absolute terms with a bonus $€ 500$ per year the associated increase in willingness to participate is substantial $(10 \%)$.

The results of the analyses that include background variables age, BMI, and sex are presented in Table 3a. These additional analyses showed that the probability of participating is positively influenced by "limiting a lifestyle program to only diabetes patients" and "by supervision and counseling of an instructor" by $13.4 \%$ and $15.8 \%$, respectively (linear probability model). Moreover, older people are less willing to participate in a lifestyle intervention program. Additional analyses showed that the increasing number of statistical significant attributes compared to Table 2 was caused by the exclusion of respondents with missing background variables and not by the case-mix adjustments (results not shown). Since it is likely that income may influence the results we also present the analysis including income. However, information on income was only available for 32 respondents (Table $3 b$ ). 
Table 3a Results of regression models based on the attributes of participation in the hypothetical lifestyle interventions: adjusted for gender, age, and $\mathrm{BMI}(\mathrm{N}=37 ; \mathrm{N}$ observations = I58)

\begin{tabular}{|c|c|c|c|c|c|c|c|}
\hline \multirow[t]{2}{*}{ Attributes } & \multicolumn{4}{|c|}{ Logistic regression model } & \multicolumn{3}{|c|}{ Linear probability model } \\
\hline & B & Odds ratio & $95 \% \mathrm{Cl}$ & $P$ value & B & $95 \% \mathrm{Cl}$ & $P$ value \\
\hline \multicolumn{8}{|l|}{ Time spent on the program } \\
\hline \multicolumn{8}{|l|}{ (reference category $=2.5$ hours) } \\
\hline 4 hours & -0.441 & 0.643 & 0.324 to 1.279 & 0.208 & -0.092 & -0.214 to 0.030 & 0.134 \\
\hline \multicolumn{8}{|l|}{ Arrangement of physical activity lessons } \\
\hline \multicolumn{8}{|l|}{ (reference category = with men and women) } \\
\hline With people of the same gender & 0.408 & 1.503 & 0.570 to 3.975 & 0.409 & 0.069 & -0.093 to 0.232 & 0.389 \\
\hline Individually & -0.009 & 0.991 & 0.317 to 3.099 & 0.987 & 0.011 & -0.177 to 0.199 & 0.908 \\
\hline \multicolumn{8}{|l|}{ Group activity } \\
\hline \multicolumn{8}{|l|}{ (reference category = only with people without diabetes) } \\
\hline Only with other diabetes patients & 0.735 & 2.085 & 0.975 to 4.459 & 0.058 & 0.134 & 0.008 to $0.26 \mathrm{I}$ & 0.038 \\
\hline \multicolumn{8}{|l|}{ Sports activity } \\
\hline \multicolumn{8}{|l|}{ (reference category = walking/cycling) } \\
\hline Fitness (treadmill, rowing machine, bicycle) & 0.577 & 1.780 & 0.75 I to 4.225 & 0.191 & 0.095 & -0.053 to 0.244 & 0.202 \\
\hline \multicolumn{8}{|l|}{ Counseling } \\
\hline \multicolumn{8}{|l|}{ (reference category = no counseling) } \\
\hline Counseling from a physical therapist/sports instructor & 1.01 & 2.746 & 1.094 to 6.876 & 0.031 & 0.158 & 0.009 to 0.307 & 0.038 \\
\hline Money & 0.008 & 1.008 & 1.002 to 1.015 & 0.010 & 0.001 & 0.000 to 0.002 & 0.001 \\
\hline \multicolumn{8}{|l|}{ Copayment $=€ 500$ per year } \\
\hline \multicolumn{8}{|l|}{ Copayment $=€ 327.50$ per year } \\
\hline \multicolumn{8}{|l|}{ Copayment $=€ I 55$ per year } \\
\hline \multicolumn{8}{|l|}{$€ 0$ per year } \\
\hline \multicolumn{8}{|l|}{ Bonus $=€ 155$ per year } \\
\hline \multicolumn{8}{|l|}{ Bonus $=€ 327.50$ per year } \\
\hline \multicolumn{8}{|l|}{ Bonus $=€ 500$ per year } \\
\hline Receiving & -1.417 & 0.230 & 0.068 to 0.857 & 0.028 & -0.243 & -0.486 to -0.001 & 0.049 \\
\hline Interaction receiving*money & -0.007 & 0.993 & 0.986 to 0.999 & 0.030 & -0.001 & -0.002 to 0.000 & 0.061 \\
\hline Gender & -0.262 & 0.770 & 0.331 to 1.790 & 0.543 & -0.064 & -0.208 to 0.079 & 0.368 \\
\hline \multicolumn{8}{|l|}{ (reference category = women) } \\
\hline Age & -1.417 & 0.242 & 0.064 to 0.918 & 0.037 & -0.236 & -0425 to -0.047 & 0.016 \\
\hline \multicolumn{8}{|l|}{ (reference category $<75$ years of age) } \\
\hline BMI & -0.360 & 0.698 & $0.24 I$ to 2.014 & 0.506 & -0.048 & -0237 to 0.141 & 0.611 \\
\hline \multicolumn{8}{|l|}{ (reference category $<$ BMI $30 \mathrm{~kg} / \mathrm{m}^{2}$ ) } \\
\hline Intercept & -0.272 & 0.762 & 0.202 to 2.863 & 0.687 & 0.418 & 0.168 to 0.669 & 0.002 \\
\hline
\end{tabular}

Abbreviations: $\mathrm{BMI}$, body mass index; $\mathrm{Cl}$, confidence interval; $€$, euro.

Even in this analysis with fewer respondents the effect of money on willingness to participate remains.

It is worth noting, however, that in Tables $3 a$ and $3 b$ the dummy variable "receiving" seems statistically significant. This seems to indicate that the zero option ('not having to pay a copayment' in case of copayments or 'not receiving a bonus' in case of bonuses) is valued lower by respondents that received a questionnaire including bonuses compared with respondents that received a questionnaire with copayments.

\section{Discussion}

Lifestyle intervention programs can have a positive impact on public health but program participation is often quite low. This study investigated the factors, particular financial factors, underlying type 2 diabetes patients' willingness to participate in a lifestyle program. A conjoint analysis was applied to measure respondents' preferences regarding a lifestyle program. This study explored empirically potential differences between positive (bonus) and negative (copayment) financial incentives on diabetes patients' willingness to participate in lifestyle intervention programs.

The main finding of this study suggests that copayment is inversely related to the willingness to participate in a lifestyle intervention program. In other words, copayment can discourage participation in the program. This finding is consistent with an earlier finding using conjoint analysis, which showed unwillingness to pay by high-risk individuals for diabetes riskreduction programs. ${ }^{16}$ Receiving a bonus seems to be associated with a higher willingness to participate in the program although the coefficients for each euro received is smaller 
Table 3b Results of regression models based on the attributes of participation in the hypothetical lifestyle interventions: adjusted for gender, age, $\mathrm{BMI}$, and income $(\mathrm{N}=32 ; \mathrm{N}$ observations $=125)$

\begin{tabular}{|c|c|c|c|c|c|c|c|}
\hline \multirow[t]{2}{*}{ Attributes } & \multicolumn{4}{|c|}{ Logistic regression model } & \multicolumn{3}{|c|}{ Linear probability model } \\
\hline & B & Odds ratio & $95 \% \mathrm{Cl}$ & $P$ value & B & $95 \% \mathrm{Cl}$ & $P$ value \\
\hline \multicolumn{8}{|l|}{ Time spent on the program } \\
\hline 4 hours & -0.335 & 0.715 & 0.295 to 1.735 & 0.458 & -0.084 & -0.245 to 0.0770 & 0.295 \\
\hline \multicolumn{5}{|l|}{ (reference category = with men and women) } & & & \\
\hline With people of the same gender & 0635 & 1.887 & 0.526 to 6.773 & 0.330 & 0.097 & -0.111 to 0.305 & 0.349 \\
\hline Individually & 0.444 & 1.559 & 0.430 to 5.652 & 0.500 & 0.072 & -0.148 to 0.294 & 0.506 \\
\hline \multicolumn{8}{|l|}{ Group activity } \\
\hline Only with other diabetes patients & 0.531 & 1.701 & 0.698 to 4.145 & 0.243 & 0.101 & -0.054 to 0.257 & 0.193 \\
\hline \multicolumn{8}{|l|}{ (reference category = walking/cycling) } \\
\hline Fitness (treadmill, rowing machine, bicycle) & 0.731 & 2.077 & 0.742 to 5.818 & 0.164 & 0.116 & -0.077 to 0.310 & 0.230 \\
\hline \multicolumn{8}{|l|}{ Counseling } \\
\hline Counseling from a physical therapist/sports instructor & 0.908 & 2.482 & 0.870 to 7.078 & 0.089 & 0.152 & -0.024 to 0.329 & 0.089 \\
\hline Money & 0.009 & 1.009 & 1.001 to 1.016 & 0.021 & 0.001 & 0.000 to 0.002 & 0.002 \\
\hline \multicolumn{8}{|l|}{ Copayment $=€ 500$ per year } \\
\hline \multicolumn{8}{|l|}{ Copayment $=€ 327.50$ per year } \\
\hline \multicolumn{8}{|l|}{ Copayment $=€ I 55$ per year } \\
\hline \multicolumn{8}{|l|}{$€ 0$ per year } \\
\hline \multicolumn{8}{|l|}{ Bonus $=€ І 55$ per year } \\
\hline \multicolumn{8}{|l|}{ Bonus $=€ 327.50$ per year } \\
\hline \multicolumn{8}{|l|}{ Bonus $=€ 500$ per year } \\
\hline Receiving & -1.711 & 0.181 & 0.044 to 0.738 & 0.017 & -0.304 & -0.577 to -0.031 & 0.030 \\
\hline Interaction receiving $*$ money & -0.006 & 0.994 & 0.987 to 1.002 & 0.132 & -0.001 & -0.001 to 0.000 & 0.252 \\
\hline \multicolumn{7}{|l|}{ (reference category = women) } & 0.744 \\
\hline \multicolumn{8}{|l|}{ (reference category $<75$ years of age } \\
\hline \multicolumn{8}{|l|}{ (reference category $<$ BMI $30 \mathrm{~kg} / \mathrm{m}^{2}$ ) } \\
\hline \multicolumn{8}{|l|}{ Income } \\
\hline (reference category = low income) & 0.427 & 1.533 & 0.405 to 5.789 & 0.529 & 0.071 & -0.152 to 0.294 & 0.522 \\
\hline Intercept & -0.463 & 0.629 & 0.130 to 3.056 & 0.566 & 0.410 & 0.097 to 0.723 & 0.012 \\
\hline
\end{tabular}

Abbreviations: $\mathrm{BMI}$, body mass index; $\mathrm{Cl}$, confidence interval; $€$, euro.

compared with the negative coefficients of copayments. This result seems also consistent with findings in the literature. Rewards for following a lifestyle program are less effective in contrast to rewards for attendance of vaccination or screening programs,${ }^{28}$ and there is insufficient evidence of the effectiveness of rewards to promote lifestyle changes. ${ }^{29-31}$ The analysis corrected for potential confounders like age, BMI, sex, and income showing that the main conclusion does not change.

A strength of this study is that the conjoint analysis included both a copayment and a bonus. This enabled a test for possible differences between positive and negative incentives. The main advantage of a conjoint analysis is that it can be used to gain insights in the relative importance of intervention attributes and the way people value these attributes.

A limitation of this study is the small group of respondents. Although the 174 observations are sufficient to report the results on the vignette-level, a proper analysis among subgroups of patients requires a much larger sample..$^{32-34}$ Factors underlying willingness to participate in a lifestyle intervention should be studied more extensively. Therefore further research should preferably use larger samples facilitating analysis of relevant subgroups. Another limitation of this study is the limited knowledge on the external validity of the answers of the conjoint analysis. To what extent do the answers reflect hypothetical scenario choices made in 
everyday life? Although progress in comparing, stated in a questionnaire, with revealed preferences (people's actual behavior) has been performed in other healthcare settings, ${ }^{35}$ evidence in the field of health promotion is scarce. Therefore empirical research to test for potential differences between the impact of copayments and bonuses on willingness to participate in lifestyle intervention programs using revealed preferences compared with stated preferences is encouraged.

It would be interesting if future research could explore the differences in respondents' values for not having to pay to participate (related to scenarios with a bonus) compared to having to pay a copayment (related to scenarios with copayments). It is worth taking these differences into account in study designs as this sample was split, but one could consider testing if this result remains the same if the same people value zeros compared with a bonus and with a copayment.

\section{Conclusion}

This study showed that financial considerations may influence willingness to participate in lifestyle intervention programs. Copayments could therefore discourage participation. Although the positive impact of bonuses is smaller than the negative impact of copayments, bonuses could still be used to encourage willingness to participate.

\section{Disclosure}

The authors report no conflicts of interest in this work.

\section{References}

1. Toobert DJ, Glasgow RE, Strycker LA, Barrera M Jr, Ritzwoller DP, Weidner G. Long-term effects of the Mediterranean lifestyle program: a randomized clinical trial for postmenopausal women with type 2 diabetes. Int J Behav Nutr Phys Act. 2007;4:1.

2. Pi-Sunyer X, Blackburn G, Brancati FL, et al. Reduction in weight and cardiovascular disease risk factors in individuals with type 2 diabetes: one-year results of the look AHEAD trial. Diabetes Care. 2007;30(6):1374-1383.

3. Davies MJ, Heller S, Skinner TC, et al. Effectiveness of the diabetes education and self management for ongoing and newly diagnosed (DESMOND) programme for people with newly diagnosed type 2 diabetes: cluster randomised controlled trial. BMJ. 2008;336(7642):491-495.

4. Diabetes Prevention Program Research Group. The Diabetes Prevention Program (DPP): description of lifestyle intervention. Diabetes Care. 2002;25(12):2165-2171.

5. Knowler WC, Barrett-Connor E, Fowler SE, et al. Reduction in the incidence of type 2 diabetes with lifestyle intervention or metformin. N Engl J Med. 2002;346(6):393-403.

6. Lindstrom J, Ilanne-Parikka P, Peltonen M, et al. Sustained reduction in the incidence of type 2 diabetes by lifestyle intervention: follow-up of the Finnish Diabetes Prevention Study. Lancet. 2006;368(9548): 1673-1679.

7. Wild S, Roglic G, Green A, Sicree R, King H. Global prevalence of diabetes: estimates for the year 2000 and projections for 2030. Diabetes Care. 2004;27(5):1047-1053.
8. Zhao G, Ford ES, Li C, Mokdad AH. Compliance with physical activity recommendations in US adults with diabetes. Diabet Med. 2008;25(2):221-227.

9. Mokdad AH, Bowman BA, Ford ES, Vinicor F, Marks JS, Koplan JP. The continuing epidemics of obesity and diabetes in the United States. JAMA. 2001;286(10):1195-1200.

10. Javaher P, Seidel G, Dierks ML. Participation in disease management of a health insurance company: characteristics and assessment of the process and outcome parameters in the programme. $J$ Public Health. 2006;14(1):37-42.

11. Icks A, Rathmann W, Haastert B, et al. Clinical and cost-effectiveness of primary prevention of Type 2 diabetes in a 'real world' routine healthcare setting: model based on the KORA Survey 2000. Diabet Med. 2007;24(5):473-480.

12. Phillips KA, Maddala T, Johnson FR. Measuring preferences for health care interventions using conjoint analysis: an application to HIV testing. Health Serv Res. 2002;37(6):1681-1705.

13. Bishop AJ, Marteau TM, Armstrong D, et al. Women and health care professionals' preferences for Down's Syndrome screening tests: a conjoint analysis study. BJOG. 2004;111(8):775-779.

14. van den Berg B, Al M, van Exel J, Koopmanschap M, Brouwer W. Economic valuation of informal care: conjoint analysis applied in a heterogeneous population of informal caregivers. Value Health. 2008;11(7):1041-1050.

15. van den Berg B, Van Dommelen P, Stam P, Laske-Aldershof T, Buchmueller T, Schut FT. Preferences and choices for care and health insurance. Soc Sci Med. 2008;66(12):2448-2459.

16. Johnson FR, Manjunath R, Mansfield CA, Clayton LJ, Hoerger TJ, Zhang P. High-risk individuals' willingness to pay for diabetes riskreduction programs. Diabetes Care. 2006;29(6):1351-1356.

17. Ziebland S, Thorogood M, Yudkin P, Jones L, Coulter A. Lack of willpower or lack of wherewithal? "Internal" and "external" barriers to changing diet and exercise in a three year follow-up of participants in a health check. Soc Sci Med. 1998;46(4-5):461-465.

18. Chinn DJ, White M, Harland J, Drinkwater C, Raybould S. Barriers to physical activity and socioeconomic position: implications for health promotion. J Epidemiol Community Health. 1999;53(3):191-192.

19. Schmidt $\mathrm{H}$. Bonuses as incentives and rewards for health responsibility: a good thing? J Med Philos. 2008;33(3):198-220.

20. Ryan M, Major K, Skatun D. Using discrete choice experiments to go beyond clinical outcomes when evaluating clinical practice. J Eval Clin Pract. 2005;11(4):328-338.

21. Culos-Reed SN, Rejeski WJ, McAuley E, Ockene JK, Roter DL. Predictors of adherence to behavior change interventions in the elderly. Control Clin Trials. 2000;21(5 Suppl):200S-205S.

22. Ferrand C, Perrin C, Nasarre S. Motives for regular physical activity in women and men: a qualitative study in French adults with type 2 diabetes, belonging to a patients' association. Health Soc Care Community. 2008;16(5):511-520.

23. Jones M, Jolly K, Raftery J, Lip GY, Greenfield S; BRUM Steering Committee. 'DNA' may not mean 'did not participate': a qualitative study of reasons for non-adherence at home- and centre-based cardiac rehabilitation. Fam Pract. 2007;24(4):343-357.

24. Nagelkerk J, Reick K, Meengs L. Perceived barriers and effective strategies to diabetes self-management. $J$ Adv Nurs. 2006;54(2): $151-158$.

25. Marsh LC, Cormier DR. Spline Regression Models. Thousand Oaks, CA: Sage Publications, Inc; 2002.

26. Struijs JN, van Til JT, Baan CA. Experimenting with a Bundled Payment System for Diabetes Care in The Netherlands: The First Tangible Effects. 2009. Available from: http://www.rivm.nl/bibliotheek/ rapporten/260224002.pdf. Accessed September 6, 2011.

27. Struijs JN, Baan CA. Integrating care through bundled paymentslessons from The Netherlands. N Engl J Med. 2011;364(11): 990-991.

28. Voigt K. Incentives, health promotion and equality. Health Econ Policy Law. 2010:1-21. 
29. Jochelson K. Paying the patient: improving health using financial incentives. 2007. Available from: http://www.wpro.who.int/NR/rdonlyres/ BCC2F5C3-B685-684FF1-AE77-39C52F4ED247/0/payingthepatient. pdf. Accessed September 2, 2011.

30. Sutherland K, Leatherman S, Christianson J. Paying the Patient: Does it Work? A Review of Patient-Targeted Incentives. London, UK: The Health Foundation; 2008.

31. Wilkinson E. Can you pay people to be healthy? Lancet. 2008;371(9621): 1325-1326.

32. Ryan M, Diack J, Watson V, Smith N. Rapid prenatal diagnostic testing for Down syndrome only or longer wait for full karyotype: the views of pregnant women. Prenat Diagn. 2005;25(13):1206-1211.

33. Baltussen R, Stolk E, Chisholm D, Aikins M. Towards a multi-criteria approach for priority setting: an application to Ghana. Health Econ. 2006;15(7):689-696.
34. Cheraghi-Sohi S, Bower P, Mead N, McDonald R, Whalley D, Roland M. Making sense of patient priorities: applying discrete choice methods in primary care using 'think aloud' technique. Fam Pract. 2007;24(3):276-282.

35. Blumenschein K, Blomquist GC, Johannesson M, Horn N, Freeman P. Eliciting willingness to pay without bias: evidence from a field experiment. Econ J. 2008;118(525):114-137.

36. Lambooij M, Flache A, Sanders K, Siegers J. Encouraging employees to co-operate: the effects of sponsored training and promotion practices on employees' willingness to work overtime. Int J Hum Resource Manage. 2007;18(10):1748-1767.

37. van den Berg B, Al M, Brouwer W, van Exel J, Koopmanschap M. Economic valuation of informal care: the conjoint measurement method applied to informal caregiving. Soc Sci Med. 2005;61(6):1342-1355. 


\section{Appendix A}

\section{Design conjoint analysis: attributes and levels}

The combination of six attributes and levels (two attributes with four levels, one attribute with three levels, and one attribute with four levels) gave rise to $2^{4} \times 3^{1} \times 4^{1}=192$ hypothetical lifestyle intervention programs (possible scenarios). Each participant randomly received a set of four out of 48 sets of scenarios (the 192 scenarios were clustered in 48 sets of four scenarios).

One of the challenges in designing a conjoint analysis experiment is to avoid the combination of unrealistic attributes and levels in one scenario. ${ }^{36}$ In order to make sure that presented scenarios were realistic, several items were rephrased. Another design challenge is to avoid respondents being confronted with scenario-attributes that are similar (similarity in the set of four scenarios they received), resulting in reduced motivation for the respondents due to a boring task. Therefore, it was tested if more than three questionnaires had four or more scenario-attributes that were similar. If this was the case, a new randomization was started. A second measure was that the questionnaires were constructed by multiple vignetteuniverses (ie, a set of all possible vignette combinations): five datasets with the 192 vignettes were constructed and they were each separately randomly ordered. This meant that each unique vignette could be rated five times, but that it was always combined with other vignettes. This decreased the risk that any vignette was combined more than once with other vignettes that were similar. So even when a vignette was judged by a respondent who became less motivated because of too little variation between the vignettes, a similar vignette would be judged by another respondent who was still motivated because the choices in their questionnaire varied sufficiently.

\section{Conjoint analysis: survey questions}

Respondents were first asked to rate the four hypothetical lifestyle interventions with a grade ranging from " 1 " to " 10 ," where " 1 " was defined as really dislike the lifestyle intervention and " 10 " as really like the lifestyle intervention. The rating exercise measures which aspects of the lifestyle intervention participants valued. ${ }^{14,37}$ Subsequently, respondents were asked whether or not they would be willing to participate in the hypothetical lifestyle interventions (answering categories "yes" or "no").

A communication expert was consulted to adjust the wording of the conjoint analysis questionnaire in an attempt to avoid bias due to incorrect interpretation of the conjoint questions. Figure A1 presents an example of a hypothetical life style intervention (a scenario).

\begin{tabular}{|l|}
\hline \multicolumn{1}{|c|}{\begin{tabular}{|c|} 
Program 1 \\
10100
\end{tabular}} \\
\hline The program will take you 4 hours per week (including travel time) \\
\hline The program will take place in a group of men and women \\
\hline You will exercise (more) with other diabetes patients \\
\hline You will walk/cycle during the program \\
\hline While exercising, you will be supervised by a sports instructor or a physiotherapist \\
\hline You will have to pay $€ 327.50$ per year to participate in the program \\
\hline
\end{tabular}

1. Grade program 1 ( 1 indicates really dislikes the program and 10 indicates really likes the program $)^{*}$

$\begin{array}{llllllllll}1 & 2 & 3 & 4 & 5 & 6 & 7 & 8 & 9 & 10 \\ \square & \square & \square & \square & \square & \square & \square & \square & \square & \square\end{array}$

2. Would you be willing to participate in program 1 ?

$$
\square \text { yes } \quad \square \text { no }
$$

Figure Al Example scenario.

Note: *Results were not used in this paper. 


\section{Appendix B}

\section{Spline in regression models}

A spline enables a test of whether the slope of a negative financial incentive ("copayment") differs from the slope of a positive financial incentive ("bonus") for participation in the hypothetical lifestyle intervention (scenario). ${ }^{25}$ The main reason for including a spline is that people might react differently to a scenario when they are asked to pay compared with receiving money for a similar scenario. A spline was constructed using three variables. The first variable expressed the amount of money received or paid (ranging from $-€ 500$ to $€ 500$; see Table 1). By means of this variable, the association between the amount of money and the probability of participation in the lifestyle intervention is tested. The second variable is a dummy with the value 0 in case of a set of scenarios stating that the respondents would have to pay vs the value 1 for scenarios indicating that people would receive money in return for participation in the lifestyle intervention program. This dummy is called the "knot" and it defines the place where the slope of the model may change. Third, an interaction of these two variables was entered into the logistic regression analyses. When the slope before the knot (here: negative values of money, or the negative side of the $\mathrm{x}$-axis) differs from the slope after the knot (here: positive values of money, or the positive side of the $\mathrm{x}$-axis), this interaction will yield a statistically significant result. Together these three variables enable a test of whether the slopes and the continuance of the logistic regression analyses differ between negative and positive financial incentives for participation in hypothetical lifestyle intervention programs.

\section{Publish your work in this journal}

Patient Preference and Adherence is an international, peer-reviewed, open access journal focusing on the growing importance of patient preference and adherence throughout the therapeutic continuum. Patient satisfaction, acceptability, quality of life, compliance, persistence and their role in developing new therapeutic modalities and compounds to optimize clinical outcomes for existing disease states are major areas of interest. This journal has been accepted for indexing on PubMed Central. The manuscript management system is completely online and includes a very quick and fair peer-review system. Visit http://www.dovepress.com/ testimonials.php to read real quotes from published authors. 